\title{
Combined Measures of Psychomotor and Cognitive Alterations as a Potential Hallmark for Bipolar Depression
}

\author{
Alison Robin ${ }^{1,2}$, Anne Sauvaget ${ }^{1,2}$, Thibault Deschamps ${ }^{1}$, \\ Samuel Bulteau ${ }^{2}$, and Véronique Thomas-Ollivier ${ }^{\circledR}$ \\ 'Laboratory "Movement, Interactions, Performance" (E.A. 4334), Faculty of Sport Sciences, University of Nantes, Nantes, France \\ ${ }^{2}$ Addictology and Liaison Psychiatry Department, University Hospital Nantes, Nantes, France
}

Objective The current study aimed to examine whether specific features of psychomotor retardation (PMR) and cognitive functioning established different profiles in unipolar (UD) and bipolar depression (BD).

Methods Two groups of age-matched patients with UD ( $\mathrm{n}=54)$ and $\mathrm{BD}(\mathrm{n}=20)$ completed the Montgomery-Asberg Depression Rating Scale (MADRS/60), the Montreal Cognitive Assessment (MoCA/30), and the Salpêtrière Retardation Rating Scale (SRRS/60). We analyzed the group effect and then performed intra-group analyses.

Results The BD patients have higher SRRS score, and lower MoCA score than UD despite no difference on the level of depression between UD and BD. Our results show that PMR can be predicted by the level of depression in UD and by the cognitive alteration and onset of disease in BD.

Conclusion PMR is a relevant marker of depression. Our results highlight the importance of concomitant evaluation of psychomotor and cognitive functions in the distinction of UD and BD symptoms.

Psychiatry Investig 2019;16(12):954-957

Key Words Psychomotor retardation, Unipolar depression, Bipolar depression, Cognitive functions.

\section{INTRODUCTION}

Psychomotor retardation (PMR) is described as a central symptom in depression. ${ }^{1}$ PMR has a negative impact on quality of life in both social and professional functioning. ${ }^{2}$ Moreover, it appears to be a solid indicator of the transition to chronicity. ${ }^{3}$ Its assessment in clinical settings is of crucial importance for the patient's quality of life. Psychomotor disturbance is characterized by impairments in motor, cognitive and verbal functioning ${ }^{4}$ expressed through agitation or retardation symptoms in bipolar (BD) and unipolar depressions (UD). Distinguishing unipolar from bipolar patients is a major clinical issue. Indeed, the lack of relevant markers of $\mathrm{BD}$

Received: May 13, 2019 Revised: October 3, 2019

Accepted: November 7, 2019

$\triangle$ Correspondence: Veronique Thomas-Ollivier, $\mathrm{PhD}$

Laboratory "Movement, Interactions, Performance" (UPRES-E.A. 4334), Faculty of Sport Science, University of Nantes, 25 bis boulevard Guy Mollet, BP 72206, 44322 Nantes Cedex 3, France

Tel: +33 (0)2 518372 14, Fax: +33 (0)2 51837045

E-mail: veronique.thomas-ollivier@univ-nantes.fr

(c) This is an Open Access article distributed under the terms of the Creative Commons Attribution Non-Commercial License (https://creativecommons.org/licenses/by$\mathrm{nc} / 4.0$ ) which permits unrestricted non-commercial use, distribution, and reproduction in any medium, provided the original work is properly cited. leads to misdiagnosis of the illness. When a bipolar patient is assessed in a depressive phase, on the absence of manic or hypomanic previous episodes, there is a relative risk of more than $40 \%$ of being mistakenly diagnosed as unipolar depression. ${ }^{5}$ Indeed, the diagnostic criteria for depressive episodes defined the American Psychiatric Association ${ }^{6}$ does not discriminate unipolar and bipolar disorders. In order to propose clinical leads to help the distinction between UD and BD, our study focuses on Salpêtrière Retardation Rating Scale ${ }^{7}$ (SRRS) which allows to explore all facets of the retardation component of PMR. This symptom is described in both populations, and sometimes identified as more prone in $\mathrm{BD},{ }^{8,9}$ or similar in other studies. ${ }^{10,11}$ This study aims to test if PMR in relation with the level of depression and cognition, is a relevant feature in unipolar and bipolar depression. ${ }^{11,12}$

\section{METHODS}

\section{Participants}

Fifty-four outpatients with UD and 20 patients with BD were recruited in the Addictology and Liaison-Psychiatry department of the University Hospital of Nantes. All of these 
patients had a long history of illness. Inclusion criteria were: 1-diagnosis of bipolar disorder or unipolar disorder, according to the DSM-5; 2-age over 18 years old; 3-a score superior or equal to 20 on the Montgomery-Asberg Depression Rating Scale (MADRS); ${ }^{13} 4$-a cognitive score superior or equal to 10 on Montreal Cognitive Assessment (MoCA). ${ }^{14}$ Exclusion criteria were: 1-presence of psychotic disorders or addiction; 2-presence of neurodegenerative disorders. All participants provided informed consent for the study.

Evaluation criteria: SRRS, is a 15 items scale (/60) that encompass the clinical diversity of this symptom by measuring motor, ideational and verbal behavior. The presence of a PMR is notified with a score $\geq 20 .{ }^{15}$ MoCA is a brief test (/30) covering most cognitive domains that may be impaired in subjects with mild or severe cognitive impairment irrespective of etiology. Neurocognitive impairment is excluded beyond $26 / 30$.

\section{Data analysis}

Due to the skewed distribution of several continuous variables, to the test the effects of group (UD vs. BD) on age, MADRS, MoCA, SRRS and age of onset, the Mann-Whitney sum rank test were carried out (Table 1).

To explore the relationship between aforesaid dependent variables in UD and $\mathrm{BD}$, simple correlation was used as a first step and was completed by multilinear regression analysis to explain the relationship between SRRS as dependent variable and age, MoCA, MADRS and age of onset as predictors.

Additionally, UD and BD retardation sub-groups (SRRS score $\geq 20$ ) were compared on each item of the SRRS using the Mann-Whitney sum rank test.

\section{RESULTS}

Our results revealed that $\mathrm{BD}$ patients have higher psychomotor retardation (SRRS; $\mathrm{p}=0.042$ ), and lower cognitive score (MoCA; $\mathrm{p}=0.029)$ than UD.

In addition, in the UD group, the correlation analysis revealed a link between SRRS and MADRS ( $r=0.69, \mathrm{p}<0.001)$, a correlation between MoCA, Age and Onset the disease (MoCA/age: $\mathrm{r}=-0.39, \mathrm{p}=0.01$; MoCA/onset of the disease: $\mathrm{r}=-0.45, \mathrm{p}<0.01$; age/onset of the disease: $\mathrm{r}=0.37, \mathrm{p}<0.01$ ). In the $\mathrm{BD}$, a significant correlation appears between SRRS and MoCA ( $\mathrm{r}=-0.65, \mathrm{p}<0.01)$, age of onset and MADRS $(\mathrm{r}=0.51, \mathrm{p}<0.05)$; age of onset and SRRS $(\mathrm{r}=0.66, \mathrm{p}<0.01)$, and age and MADRS $(\mathrm{r}=0.45, \mathrm{p}<0.05)$.

The multilinear regression analysis in UD (MoCA, MADRS, age and onset of disease as predictor of SRRS) $[\mathrm{F}(4,49)=10.26$, $\mathrm{p}<0.01, \mathrm{R}^{2}=0.49$ ] showed that MADRS significantly predicted SRRS ( $\mathrm{p}<0.001, \beta=0.71$ ). The same analysis was performed in $\mathrm{BD}$ group and MADRS, age and onset of the disease as predictor to SRRS [F $\left.(4.15)=10.05, \mathrm{p}<0.01, \mathrm{R}^{2}=0.74\right]$. These results

Table 1. Baseline characteristics and group effects (Mann-Whitney sum rank test) in UD and BD

\begin{tabular}{|c|c|c|c|}
\hline & $\mathrm{UD}(\mathrm{N}=54)$ & $\mathrm{BD}(\mathrm{N}=20)$ & p-value \\
\hline Female gender, N (\%) & $37(68.5)$ & $10(50)$ & \\
\hline Age (years), mean $\pm S D$ & $53.5 \pm 11.9$ & $57.2 \pm 12.8$ & 0.228 \\
\hline MADRS score $(/ 60)$, mean $\pm S D$ & $28.5 \pm 5.4$ & $30.7 \pm 5.9$ & 0.145 \\
\hline SRRS score $(/ 60)$, mean $\pm S D$ & $22.51 \pm 9.18$ & $28.40 \pm 9.73$ & $0.042^{*}$ \\
\hline MoCA score $(/ 30)$, mean \pm SD & $26.21 \pm 2.87$ & $23.68 \pm 4.84$ & $0.029^{*}$ \\
\hline Age of onset & $36.76 \pm 14.91$ & $33.20 \pm 17.41$ & 0.342 \\
\hline \multicolumn{4}{|l|}{ Treatments (\%) } \\
\hline Monoamine oxidase inhibitors & 0 & 0 & \\
\hline Tricyclic antidepressants & 28.57 & 0 & \\
\hline Selective serotonin reuptake & 0 & 0 & \\
\hline \multicolumn{4}{|l|}{ Inhibitors } \\
\hline \multicolumn{4}{|l|}{ Serotonin-norepinephrine } \\
\hline Reuptake inhibitors & 39.29 & 33.33 & \\
\hline Other antidepressants & 35.71 & 16.67 & \\
\hline Mood stabilizers & 14.29 & 50 & \\
\hline Benzodiazepines & 67.86 & 83.33 & \\
\hline Antipsychotics & 42.86 & 66.67 & \\
\hline
\end{tabular}

${ }^{*} \mathrm{p}<0.05$. MADRS: Montgomery-Asberg Depression Rating Scale, SRRS: Salpêtrière Retardation Rating Scale, MoCA: Montreal Cognitive Assessment, UD: unipolar depression, BD: Bipolar depression 
show MoCA $(\beta=-0.55 ; p<0.01)$ and Onset of the disease $(\beta=0.61, \mathrm{p}<0.01)$ significantly predicted SRRS.

Finally, the retardation subgroups were compared using the Mann-Whitney sum rank test for all the SRRS items. No difference between subgroups was found whatever the item (all $\mathrm{p}$ values $>0.05$ ).

\section{DISCUSSION}

The main outcome of this study is the presence of more severe psychomotor and cognitive impairment in bipolar depression. The other variables measured (age, severity of depression, and age of onset) do not differ in UD ( $\mathrm{n}=54)$ and $\mathrm{BD}(\mathrm{n}=20)$ patients (Table 1). These results are in accordance with studies focusing on the level of daily physical activity, the gross movement dexterity, ${ }^{9}$ the verbal fluency performance ${ }^{16}$ as well as cognitive skills associated with PMR such as attention, and executive functions. ${ }^{17}$

The higher percentage of bipolar patients with PMR in our study (score>20; BD: 85\%; UD: 59.3\%), and classically observed in the literature, could explain, in part, the group effect on the SRRS. In the UD, the multivariate regression model reveals that the SRRS performance can be predicted by the level of depression. This result highlights the close link between depressive and psychomotor symptoms in unipolar depression and support the diagnostic value of PMR. In BD, the analysis reveals a correlation between SRRS and MoCA. This was confirmed by multivariate regression model, SRRS score can be predicted by the MoCA and age of onset. These results suggest a singular link between cognition and retardation in bipolar depressives' patients and are in accordance with the literature showing impairments in processing speed, ${ }^{18}$ executive functions $^{19}$ or visual attention ${ }^{20}$ in this population. Different explanations are provided in the literature such as the effect of the family history, the earlier onset of disorder, the number of manic episodes or the substance abuse, ${ }^{21}$ which could involve greater cognitive scars in bipolar patients.

In our naturalistic study, the onset of disease doesn't differ between groups and substance abuse during the protocol is an exclusion criteria. This doesn't exclude the possibility of previous abuses. Indeed, it has been shown that BD patients are more prone to substance abuse in their history of illness. ${ }^{22}$

Neurobiological studies have also shown differences between unipolar and bipolar patients, ${ }^{23,24}$ such as a greater reduction of grey matter volume in the inferior frontal gyrus, precentral gyrus ${ }^{25}$ and cerebellum ${ }^{26,27}$ which could imply that PMR is expressed differently depending on the type of depression. The PMR can sometimes manifest itself either through more important cognitive retardation or through more significant motor retardation; ${ }^{28,29}$ but both cognitive and motor retar- dation are, in some measure, always present. ${ }^{30}$ We show the importance to evaluate PMR and cognitive functions together in clinical practice to get more diagnostic leads.

We acknowledge some limitations in our study. First, bipolar and unipolar patients did not have the same treatment, which could have an impact on the expression of the psychomotor retardation. ${ }^{31-34}$ Furthermore, some patients with unipolar depression may be re-diagnosed as bipolar in the future; a followup would have been very helpful for accurate diagnosis.

Our study shows that the PMR is a potential tool for discrimination between the two populations. Its characterization is a crucial challenge to better understand the underlying neurobiological mechanisms and to improve diagnosis. Further research with larger samples and more targeted evaluations are needed. Indeed, clinicians often use hetero-evaluation scales which lack sensitivity to optimize PMR evaluation for diagnosis. We are currently working on the implementation of a test combining psychomotor and cognitive assessments. The challenge is to choose the most appropriate combination for the co-evaluation of symptoms.

\section{Acknowledgments}

The research was supported by grants from the Region of Pays de la Loire and the University of Nantes (France).

\section{Conflicts of Interest}

The authors have no potential conflicts of interest to disclose.

\section{Author Contributions}

Conceptualization: Véronique Thomas-Ollivier, Alison Robin. Data curation: Alison Robin. Formal analysis: Thibault Deschamps. Funding acquisition: Thibault Deschamps. Investigation: Alison Robin. Methodology: Anne Sauvaget. Project administration: Véronique Thomas-Ollivier. Supervision: Véronique Thomas-Ollivier. Validation: All co-authors. Visualization: Samuel Bulteau. Writing_original draft: Alison Robin, Véronique Thomas-Ollivier. Writing_-review \& editing: Alison Robin, Véronique Thomas-Ollivier.

\section{ORCID iDs}

Véronique Thomas-Ollivier Alison Robin

https://orcid.org/0000-0003-4158-3436 https://orcid.org/0000-0002-8830-744X

\section{REFERENCES}

1. Yin Y, Yuan Y. The dopaminergic polymorphisms in psychomotor retardation of depression: a pathway-based imaging genetics association study. Eur Psychiatry 2017;41:S145-S146.

2. Kuehner C, Buerger C. Determinants of subjective quality of life in depressed patients: the role of self-esteem, response styles, and social support. J Affect Disord 2005;86:205-213.

3. Benazzi F. Psychomotor changes in melancholic and atypical depression: unipolar and bipolar-II subtypes. Psychiatry Res 2002;112:211-220.

4. Sobin C, Sackeim HA. Psychomotor symptoms of depression 156. Am J Psychiatry 1997;154:4-17.

5. Smith DJ, Ghaemi N. Is underdiagnosis the main pitfall when diagnosing bipolar disorder? Yes. BMJ 2010;340:c854.

6. American Psychiatric Association. Diagnostic and Statistical Manual of Mental Disorders DSM-5. Washington DC: American Psychiatry 
Association; 2013.

7. Widlöcher D, Ghozlan A. The Measurement of Retardation in Depression. New York: John Wiley; 1989.

8. Faurholt-Jepsen M, Brage S, Vinberg M, Christensen EM, Knorr U, Jensen HM, et al. Differences in psychomotor activity in patients suffering from unipolar and bipolar affective disorder in the remitted or mild/moderate depressive state. J Affect Disord 2012;141:457-463.

9. Sasayama D, Hori H, Teraishi T, Hattori K, Ota M, Matsuo J, et al. More severe impairment of manual dexterity in bipolar disorder compared to unipolar major depression. J Affect Disord 2012;136:1047-1052.

10. Godard J, Grondin S, Baruch P, Lafleur MF. Psychosocial and neurocognitive profiles in depressed patients with major depressive disorder and bipolar disorder. Psychiatry Res 2011;190:244-252.

11. Liu T, Zhong S, Wang B, Liao X, Lai S, Jia Y. Similar profiles of cognitive domain deficits between medication-naive patients with bipolar II depression and those with major depressive disorder. J Affect Disord 2019;243:55-61.

12. Mak ADP, Lau DTY, Chan AKW, So SHW, Leung O, Wong SLY, et al. Cognitive Impairment In Treatment-NaÏve Bipolar II and Unipolar Depression. Sci Rep 2018;8:1905.

13. Montgomery SA, Asberg M. A new depression scale designed to be sensitive to change. Br J Psychiatry 1979;134:382-389.

14. Nasreddine ZS, Phillips NA, Bédirian V, Charbonneau S, Whitehead V, Collin I, et al. The Montreal Cognitive Assessment, MoCA: a brief screening tool for mild cognitive impairment. J Am Geriatr Soc 2005; 53:695-699.

15. Pier MP, Hulstijn W, Sabbe BG. No psychomotor slowing in fine motor tasks in dysthymia. J Affect Disord 2004;83:109-120.

16. Thomas-Ollivier V, Foyer E, Bulteau S, Pichot A, Valriviere P, Sauvaget A, et al. Cognitive component of psychomotor retardation in unipolar and bipolar depression: is verbal fluency a relevant marker? Impact of repetitive transcranial stimulation. Psychiatry Clin Neurosci 2017;71:612-623.

17. Wolfe J, Granholm E, Butters N, Saunders E, Janowsky D. Verbal memory deficits associated with major affective disorders: a comparison of unipolar and bipolar patients. J Affect Disord 1987;13:83-92.

18. Canuto A, Giannakopoulos P, Moy G, Rubio MM, Ebbing K, MeilerMititelu C, et al. Neurocognitive deficits and personality traits among euthymic patients with mood disorders in late life. J Neurol Sci 2010;299:24-29.

19. Xu G, Lin K, Rao D, Dang Y, Ouyang H, Guo Y, et al. Neuropsychological performance in bipolar I, bipolar II and unipolar depression patients: a longitudinal, naturalistic study. J Affect Disord 2012;136: 328-339.

20. Kieseppä T, Mäntylä R, Tuulio-Henriksson A, Luoma K, Mantere O, Ketokivi M, et al. White matter hyperintensities and cognitive perfor- mance in adult patients with bipolar I, bipolar II, and major depressive disorders. Eur Psychiatry 2014;29:226-232.

21. Benazzi F. Clinical differences between bipolar II depression and unipolar major depressive disorder: lack of an effect of age. J Affect Disord 2003;75:191-195.

22. Messer T, Lammers G, Müller-Siecheneder F, Schmidt RF, Latifi S. Substance abuse in patients with bipolar disorder: a systematic review an meta-analysis. Psychiatry Res 2017;253:338-350.

23. Savitz JB, Drevets WC. Neuroreceptor imaging in depression. Neurobiol Dis 2013;52:49-65.

24. Savitz JB, Drevets WC. Bipolar and major depressive disorder: neuroimaging the developmental-degenerative divide. Neurosci Biobehav Rev 2009;33:699-771.

25. Lyoo IK, Kim MJ, Stoll AL, Demopulos CM, Parow AM, Dager SR, et al. Frontal lobe gray matter density decreases in bipolar I disorder. Biol Psychiatry 2004;55:648-651.

26. Delbello MP, Strakowski SM, Zimmerman ME, Hawkins JM, Sax KW. MRI analysis of the cerebellum in bipolar disorder: a pilot study. Neuropsychopharmacology 1999;21:63-68.

27. Brambilla P, Nicoletti MA, Harenski K, Sassi RB, Mallinger AG, Frank $\mathrm{E}$, et al. Anatomical MRI study of subgenual prefrontal cortex in bipolar and unipolar subjects. Neuropsychopharmacology 2002;27:792-799.

28. Caligiuri MP, Ellwanger J. Motor and cognitive aspects of motor retardation in depression. J Affect Disord 2000;57:83-93.

29. Marvel \& Paradiso. Cognitive and neurological impairment in mood disorders. Psychiatr Clin North Am 2008;183:118-122.

30. Deschamps T, Sauvaget A, Pichot A, Valrivière P, Maroulidès M, Bois A, et al. Posture-cognitive dual-tasking: a relevant marker of depression-related psychomotor retardation. An illustration of the positive impact of repetitive transcranial magnetic stimulation in patients with major depressive disorder. J Psychiatr Res 2016;83:86-93.

31. Baeken C, De Raedt R, Santermans L, Zeeuws D, Vanderhasselt MA, Meers M, et al. HF-rTMS treatment decreases psychomotor retardation in medication-resistant melancholic depression. Prog Neuro-Psychopharmacology Biol Psychiatry 2010;34:684-687.

32. Baune BT, Brignone M, Larsen KG. A network meta-analysis comparing effects of various antidepressant classes on the Digit Symbol substitution test (DSST) as a measure of cognitive dysfunction in patients with major depressive disorder. Int J Neuropsychopharmacol 2018;21:97-107.

33. Gudayol-Ferré E, Guàrdia-Olmos J, Peró-Cebollero M. Effects of remission speed and improvement of cognitive functions of depressed patients. Psychiatry Res 2015;226:103-112.

34. Sabbe B, Hulstijn W, Van Hoof J, Zitman F. Fine motor retardation and depression. J Psychiatr Res 1996;30:295-306. 